\title{
LA FORMACIÓN DE JÓVENES INVESTIGADORES Y LA EDICIÓN DE REVISTAS
}

\section{The training of young researchers and journal publishing}

\author{
Jon IGELMO-ZALDÍVAR \\ Investigador Postdoctoral del Programa «Juan de la Cierva-Incorporación». Universidad de Deusto. Bilbao. España. \\ Correspondencia: jigelmoza@deusto.es
}

Fecha de recepción: 24 de marzo de 2016

Fecha de aceptación: 31 de marzo de 2016

Fecha de Publicación: 3 de abril de 2016

Conflicto de intereses: Los autores declaran no tener conflictos de intereses

Imágenes: Los autores declaran haber obtenido las imágenes con el permiso de los pacientes

Política de derechos y autoarchivo: se permite el autoarchivo de la versión post-print (SHERPA/RoMEO)

Licencia CC BY-NC-ND. Licencia Creative Commons Atribución-NoComercial-SinDerivar 4.0 Internacional

(c) Universidad de Salamanca. Su comercialización está sujeta al permiso del editor

\section{Sr. Director:}

Fue en abril de 2013 cuando la profesora Rosa Bruno-Jofré me propuso participar como managing editor de la revista Encounters in Theory and History of Education. Acepté el reto sin pensarlo mucho. Hacía apenas cuatro meses que había comenzado una estancia de investigación postdoctoral de dos años en la Faculty of Education de la Queen's University (Canadá). Una vez superado mi primer invierno en Canadá me sentía con fuerzas para casi todo. Además conocía la publicación desde los años en que realizaba mi tesis en la Universidad Complutense de Madrid. Lo que no conocía bien era el tipo de trabajo que debería afrontar una vez había aceptado la propuesta. Lo bueno era que tenía algunos meses por delante antes de la publicación del próximo número. Recuerdo que dediqué varias semanas a revisar los números publica- dos hasta el momento por la revista, entrevistarme con miembros del anterior equipo de managing editors y estudiar los manuales del Open Journal System (OJS). La ayuda, la confianza y el respaldo que me ofreció la profesora Bruno-Jofré en este proceso fue clave.

Tras este tiempo de preparación los artículos fueron llegando a la revista. Lo que hasta el momento había sido un acercamiento abstracto en pocos meses se transformó en práctica real. Recuerdo las primeras dificultades, la desorientación que suponían dar los primeros pasos con el OJS y alguna que otra metedura de pata. Cuando en noviembre de 2013 salió publicado el volumen 14 de la revista tuve la sensación de haber dado un pequeño paso dentro de un camino de aprendizaje que me llevaría unos cuantos años de mi trayectoria académica. Con el paso del tiempo y habiendo contribuido como managing editor a tres volúmenes de Encounters in 
Theory and History of Education (2013, 2014 y 2015) sigo pensado que queda mucho camino por recorrer. Lo bueno es que la ilusión por seguir dedicando muchas horas a esta labor sigue presente. $Y$ lo mejor es que siento que sigue intacta la confianza casi ciega que Rosa Bruno-Jofré depositó en un joven investigador que acababa de llegar a Canadá para hacer una estancia postdoctoral.

La participación de investigadores en formación en tareas de edición en revistas académicas es una cuestión que podría ser mejor considerada y valorada por quienes diseñan la normativa vigente que dice lo que es y lo que no es formarse como investigador. No quiero decir con esto que el trabajo como editor sea una casilla obligatoria a rellenar en el currículum académico. Lo que pretendo es subrayar que el tipo de experiencia que aporta este tipo de responsabilidades resulta de gran importancia para tener una visión amplia y precisa del campo que dibujan las publicaciones académicas, entendidas como las herramientas que tenemos a nuestra disposición para divulgar el resultado de las investigaciones. En el caso de los investigadores predoctorales y postdoctorales, la participación activa en comités científicos, consejos editoriales, tareas de coedición o dirección de revistas, suponen un complemento a valorar en su proceso de formación. Teniendo como referencia mi propia experiencia que inicia en 2013, considero que existen diferentes ámbitos en los que la participación en procesos editoriales complementa el perfil del joven investigador. A continuación haré mención específicamente a tres:

a) el conocimiento de los tiempos editoriales;

b) la posibilidad de alcanzar una perspectiva actualizada del funcionamiento de los procesos de indexación de las revistas en las bases de datos y su inclusión en índices de impacto;

c) la mejora cualitativa de la propia investigación.

Al asumir responsabilidades en revistas académicas se profundiza en el conocimiento de los pasos que un determinado artículo debe ir dando desde su envío hasta su publicación. Lo cual resulta clave para diseñar la estrategia de divulgación y publicación de los resultados de investigación propios. Una visión más amplia del proceso, que atiende a cada uno de los matices que pueden interferir en el envío, la revisión, la edición y la publicación, ayuda a una mejor comprensión de la situación específica que un artículo puede estar experimentando en una determinada revista. De igual forma, la lectura eficaz de las revisiones ciegas recibidas o de los comentarios por parte del editor se consigue, en parte, cuando puedes intuir la intencionalidad que presentan los comentarios en cuestión. En cierta forma este tipo de conocimiento es de gran ayuda para calmar la ansiedad y evitar la precipitación que como jóvenes investigadores experimentamos cuando sentimos la presión de publicar nuestros trabajos con el fin de optar a la temida acreditación por parte de las agencias correspondientes.

Además de un conocimiento más preciso de los procesos que un artículo enfrenta para su publicación en una revista, considero que quienes en nuestros procesos de formación participamos en la edición de revistas tenemos la oportunidad de alcanzar una perspectiva actualizada del mapa del territorio que dibujan las bases de datos y los índices de impacto. Es este un mapa complejo, casi laberíntico, donde abundan tanto las pistas buenas como las pistas falsas. La desorientación que la práctica totalidad de los jóvenes investigadores hemos vivido al afrontar esta realidad y al enfrentar procesos de acreditación son la mejor muestra de la complejidad intrínseca que implica la indexación y el impacto en el contexto académico actual. Por eso, encuentro pocas formas mejores para relativizar la desazón que puede ocasionar el fenómeno cuantificador de la divulgación científica que la posibilidad de conocer desde dentro los procesos internos de las revistas en su intento por posicionarse en determinadas bases de datos e índices de impacto.

El tercer punto al que quisiera hacer mención guarda relación con las posibilidades que la participación en los procesos de edición ofrece para la mejora de los artículos que el investigador en formación desarrolla. Nada mejor en este sentido que observar desde el balcón de una revista académica la cantidad de artículos excelentes, buenos y regulares que se van recibiendo. Supone un ejercicio de contemplación singular atender a las revisiones que cada artículo recibe, las interpretaciones que los autores hacen de las revisiones, las impresiones de los lectores, etc. Aquí es donde se abre un colorido abanico de aprendizajes, algunos de ellos sutiles y llenos de matices. Es en el interior de cada revista donde la cultura de una comunidad científica 
se expresa en todo su esplendor. Merece la pena conocerlo. $Y$ merece aún más la pena que te ofrezcan la oportunidad para poder conocerlo. Pues supone una fuente de conocimiento que descubre su reflejo en el momento en que como joven investigador comienza a escribir en la pantalla del ordenador o del cuaderno las primeras líneas en la página en blanco del que será tu próximo artículo. Hace unos pocos meses, desde la dirección de la revista de Foro de Educación me propuso colaborar como coeditor del proyecto. He aceptado con gusto el desafío de implicarme en un proyecto que nace en el contexto académico español. Comienza una nueva etapa. Uno de los motivos que me lleva a aceptar esta propuesta son los importantes cambios que están aconteciendo en el paisaje que dibujan las publicaciones del campo de la educación en España. En la actualidad conviven revistas con diferentes tradiciones editoriales con nuevos proyectos que comienzan a desafiar cierto orden vigente durante la última década. Todo indica que se trata de un tiempo de transición. La forma en que los jóvenes investigadores seamos integrados o invitados a participar en los equipos editoriales de las revistas tradicionales, o bien el modo en que podamos generar nuevos espacios en base a nuestros propias perspectivas de lo que debe ser la publicación de los resultados de la investigación, marcará la configuración de los mecanismos que poseemos como comunidad académica para dar a conocer el conocimiento que generamos. Desde esta perspectiva el futuro de lo que serán las revistas de educación está más en nuestras manos de lo que parece. No puede ser de otra forma.

\section{BIBLIOGRAFÍA}

Igelmo J. La formación de jóvenes investigadores y la edición de revistas. Aula Magna 2.0 [Blog]. (18 de marzo de 2016). Recuperado de: https://cuedespyd.hypotheses.org/1309. [Citado el 24 de marzo de 2016].

Encounters in Theory and History of Education. [Internet]. En: http://library.queensu.ca/ojs/index.php/encoun ters/index. [Citado el 2 de abril de 2016].

Foro de Educación. [Internet]. En: http://forodeeducacion.com/ojs/index.php/fde/i ndex. [Citado el 2 de abril de 2016]. 